\title{
A Study on Using Noticing Hypothesis to Improve Learners' Language Input in Language Learning
}

\author{
Li Pan* \\ School of Foreign Language, China West Normal University, Nanchong 637000, Sichuan Province, China \\ *Corresponding author: Li Pan, 1375548121@qq.com
}

Copyright: () 2022 Author(s). This is an open-access article distributed under the terms of the Creative Commons Attribution License (CC BY 4.0), permitting distribution and reproduction in any medium, provided the original work is cited.

\begin{abstract}
In 1967, more than fifty years ago, Corder introduced the concept of "input" in the second language acquisition (SLA) research field. In 1985, Krashen introduced the concept of "comprehensible input hypothesis." In 1990, Schmidt introduced the concept of "noticing hypothesis" [1]. Today, "input" is becoming more and more popular in the research on second language acquisition. This paper tries to connect theories about input and noticing hypothesis in hope that the clear definition can be helpful to guide language teaching accordingly.
\end{abstract}

Keywords: Input; Noticing hypothesis; Language learning and teaching

Online publication: January 20, 2022

\section{Input and noticing}

\subsection{Input and output}

The concept of "input" was first used in the field of information technology. In 1967, Coder used it in the research on second language acquisition. For second language learners, he proposed that the most important thing is "what goes in" rather than "what is available for going in" ${ }^{[2]}$. He claimed that input is restrained by the learner and their language acquisition mechanism.

"Output" can be understood as a kind of device that is used to test the learning of learners in second language acquisition and provide them with correct feedback. Learners need to have an understanding and master the rules of the target language in the output of the language. In other words, output helps learners to pay more attention to the form of new language information ${ }^{[3]}$.

\subsection{Comprehensible input hypothesis}

Krashen's input hypothesis claims that if input is understood and there is enough of it, the necessary grammar is automatically provided. He felt that comprehensible input is crucial for language learners. In 1986, Sherwood-Smith pointed out that there are two reasons for processing input: the first is for comprehension and the second, acquisition ${ }^{[4]}$.

\subsection{Noticing hypothesis}

Schimdt's noticing hypothesis claims that people learn about the things they attend to and do not learn much from the things they do not attend to. He felt that attention is a necessary and sufficient condition to convert input into intake. Therefore, it is possible to appreciate the difference among noticing, attention, and consciousness. 
Based on the knowledge of psychology and the focus of second language acquisition research, attention is similar to consciousness. In order to clarify these concepts, Schimdt proposed that there are four levels of consciousness: intention, which includes intentional learning and incidental learning; attention, in which learners focus on something that can attract them; awareness, which means learners have a sense about stimuli; it can be divided into explicit learning and implicit learning; control, which means that learners can choose the language to use.

Based on social psychology, noticing hypothesis emphasizes on learners' intrinsic motivation and interacts between language environment and learning mechanism.

\subsection{Input in language learning}

Input is the basic for output. When learners learn a language, the amount of input determines their output. As known to all, the environment is not same when learning the first language and second language. However, in specific second language learning environment or when talking to native speakers, learners would notice that there are inconsistencies or differences between what they can express and what they need to express. Through this conscious attention activity, learners would gradually become skilled second language users.

All teaching activities in classrooms are carried out through the alternation of teaching and learning between teachers and students. Teachers are not only information providers, demonstrators, or controllers, while students are not only information receivers or silent listeners. In the teaching process, there is a dynamic cooperative relationship between teachers and students. Whether cooperation can be achieved or not mainly depends on the choice of language strategies, the transmission of communication intention, and the degree of tacit understanding between teachers and students. It also depends on students' expectation of language knowledge, motivation, proficiency in communicative topics, and the frequency of acceptance of relevant knowledge.

However, in the actual teaching process, there is always a gap between "what teachers want students to pay attention to" and "what students actually pay attention to." Upon asking for attention but not paying attention, the language activities of spontaneous attention and resistance to attention reflect the cooperative relationship between teachers and students.

\section{Second language acquisition and learning}

Acquisition refers to the incidental process where learners "pick up" a language without making any conscious effort to master it; it takes place through communicating in the second language context, and people usually think that acquisition is an unconscious learning.

Learning refers to studying with intentional effort and learning a language; it takes place in foreign language contexts, and it is thought of as a conscious learning.

Although, some may think that both acquisition and learning can take place in both the contexts. However, recently, more people are agreeing that acquisition is more important than learning in second language research.

\section{Input, noticing, and second language acquisition}

\subsection{Input and noticing}

Input is an essential part in language learning. Krashen stated that only if the input is comprehensible and sufficient, learners can then acquire the language automatically. Research has claimed that sufficient comprehensible input is good for learners' understanding of a target language. In that way, learners would acquire the knowledge about using a certain language appropriately in various situations and speaking to 
others in an appropriate way.

According to the Oxford Dictionary, noticing refers to the fact of somebody (sb) paying attention to $\mathrm{sb} /$ something (sth) or knowing about something. There are several factors that affect "noticing" in second language acquisition.

(1) Expectation: a learner's expectation and hope for sb/sth. It stimulates the learner's psychological activity, and the learner gains interest in it. In other words, they are greatly motivated by learning materials.

(2) Frequency: if a word is exposed to a learner many times, the learner would be more familiar to that word compared to other words that have been exposed less times.

(3) Perceptual silence: if a word is already known by the learner, the instant memory toward the word would come into the learner's consciousness.

(4) Skill level: when a learner has strategies in learning, the learner would learn better, thereby paying more attention to unknown fields.

(5) Task demand: a learner learns something while doing the task.

\subsection{Input and second language acquisition}

The differences between learning and acquisition have been mentioned above. It can be appreciated that when learners learn a language, input is necessary for learners to acquire the language. For example, when a child learns his or her first language, the child does not know how to speak correctly or appropriately in full sentences. As time goes by, the environment where one lives and the people around, including those who have shared conversations with, create much input for the individual; the individual then begins to have a sense of how to communicate with others in an appropriate manner. This is known as acquisition, which is different from learning.

As known, when parents teach their children a language, they do not only verbalize the words or sentences, but they tend to add some actions that can help their children understand the meaning more easily and use the terms correctly. As Krashen had claimed, learners would learn more effectively with comprehensible input.

\section{Conclusion}

\subsection{For teachers}

While organizing teaching plans, teachers should pay more attention to the interests of learners, ensure that the teaching materials are in line with the students' life, and create more activities or tasks that can help learners. In addition, teachers should provide more opportunities for students to use the target language. As students learn language through different learning materials and have different interests, teachers should teach using various methods in class. In this way, when students notice the target language, they would be able to learn it anytime and anywhere.

\subsection{For learners}

Learners should know how to find learning materials that pique their interests. They should also familiarize themselves with various learning methods for second language learning. Suitable learning materials and methods are important for second language learners. 


\section{Disclosure statement}

The author declares that there is no conflict of interest.

\section{References}

[1] Schmidt R, 1990, The Role of Consciousness in Second Language Learning. Applied Linguistics, 1990(11): 129-158.

[2] Li Z, Li Y, 2019, A Study of Input in Second Language Acquisition from the Perspective of Attentional Hypothesis. Journal of Xi'an International Studies University, 27(01): 63-67.

[3] Li T, 2013, A Review of Linguistic Output Hypothesis. Foreign Language and Literature, 29(S1): 7679.

[4] Rod E, 2015, Understanding Second Language Acquisition, Oxford University Press, Oxford.

Publisher's note

Bio-Byword Scientific Publishing remains neutral with regard to jurisdictional claims in published maps and institutional affiliations. 